\title{
Oral Health-Related Quality of Life among Parents and Teachers of Disabled Schoolchildren in Kuwait
}

\author{
Maddi Shyama $^{a}$ Sisko Honkala ${ }^{b}$ Sabiha A. Al-Mutawa ${ }^{a}$ Eino Honkala ${ }^{b}$ \\ ${ }^{a}$ National School Oral Health Program, Ministry of Health, Salmiya, and ${ }^{b}$ Faculty of Dentistry, Kuwait University, \\ Kuwait City, Kuwait
}

\section{Key Words}

Quality of life $\cdot \mathrm{GOHAI} \cdot$ Parents $\cdot$ Teachers $\cdot$ Disabled children

\begin{abstract}
Objective: The objective of this study was to assess the oral health-related quality of life between the parents and the teachers of disabled schoolchildren in Kuwait. Subjects and Methods: The three category response version of the General Oral Health Assessment Index (GOHAI) (12 questions, always, sometimes, never) was used in the questionnaires in Kuwait. Three hundred and eight (308) parents and 112 teachers were enrolled in this study. Results: The mean age of the parents was $45 \pm 9.9$ years and of the teachers $38 \pm$ 8.4 years. The mean GOHAI was $27.2 \pm 3.5$ among the parents and $27.8 \pm 3.3$ among the teachers ( $p=0.091)$. GOHAI was higher in the older age groups $(p=0.002)$ and among the parents with a university education ( $p<0.001)$. GOHAI was also higher with increasing toothbrushing frequency among the parents $(p=0.047)$ and the teachers $(p=0.003)$. Altogether, $203(66 \%)$ of the parents and 85 (76\%) of the teachers were always able to swallow comfortably; 123 (40\%) of the parents and 41 (37\%) of the teachers were able to eat without discomfort. Overall, 132 (43\%) of the parents and 41
\end{abstract}

\section{KARGER}

E-Mail karger@karger.com www.karger.com/mpp
(C) 2012 S. Karger AG, Basel 1011-7571/13/0223-0285\$38.00/0

Karger

0 pen access

This is an Open Access article licensed under the terms of the Creative Commons Attribution-NonCommercial-NoDerivs 3.0 License (www.karger.com/OA-license), applicable to the online version of the article only. Distribution for non-commercial purposes only.
(37\%) of the teachers were always pleased and happy with the looks of their teeth and gums, or dentures. The Cronbach's alpha (0.83) indicated a high degree of internal consistency between different GOHAl items. Conclusion: There seemed to be no difference in the impact of oral health on the quality of life between the parents and the teachers of disabled schoolchildren. Oral health had a relatively weak impact on the quality of life of these adults.

Copyright $\odot 2012$ S. Karger AG, Basel

\section{Introduction}

Oral health is an important part of general health and contributes to overall health-related quality of life. Measures of oral health-related quality of life (OHRQoL) are essential for oral health studies in order to provide accurate data for health promotion programs and allocation of health resources [1]. The concept of OHRQoL is significant to the clinical practice of dentistry, dental research and education. There is increasing agreement that patients' perceptions are important and should be included when assessing oral health needs and when measuring outcome [2]. This, in turn, has led to the development of instruments (questionnaires) to assess oral health status
Dr. Maddi Shyama

PO Box 1952

Salmiya 22020 (Kuwait)

E-Mail mshyama@yahoo.com 
from patients' or the public's perceptions, commonly referred to as oral health-related quality of life measures [3, 4]. Several measures to assess OHRQoL have been developed as a result of increased concern about the impact of oral conditions on a person's quality of life $[3,4]$.

The General Oral Health Assessment Index (GOHAI) is a questionnaire designed to assess the impact of oral conditions on quality of life of the elderly population [5], but later validated and widely used in a variety of adult sample groups of all ages [6]. Versions have been developed in several languages, e.g. Chinese [7], French [8], Swedish [9], Japanese [10], Malay [11], German [12] and Arabic [13]. Studies have been conducted using the GO$\mathrm{HAI}$ as an epidemiologic tool to measure oral problems [5]. GOHAI has been recommended for use as an outcome measure in several studies and in the evaluation of dental treatment. Among an elderly population, the GOHAI has been found to be a significant predictor of self-rated dental appearance [14]. The GOHAI has also been reported to be successful at detecting the impacts of oral disorders in a population of younger, relatively healthy adults [15].

Oral health has generally not been assessed as a component of general health-related quality of life instruments. Oral diseases affect not only the health of teeth, but also the consequences of dentition related to chewing and discomfort, and affect everyday life including patient's functioning and well-being. When oral health is compromised, overall health and quality of life may be diminished. Only a small number of OHRQoL studies have been conducted in the Middle-East countries like Saudi Arabia [13, 16], Jordan [17], Syria and Egypt [16].

Previous studies in Kuwait have shown high caries prevalence in children [18], high prevalence of oral diseases in adults [19] and poor oral health in disabled children and young adults [20, 21]. In an earlier study on $\mathrm{Ku}-$ waiti adults, the majority reported multiple oral health problems and less than $10 \%$ reported to have no perceived oral health problems [22]. No information is available on the OHRQoL from Kuwait, which indicates that this area of health has not received enough attention in this region. Since the perception of quality of life has a subjective component and could vary from one culture to another [23], obtaining baseline information from Kuwait is important and research at the conceptual level is essential as the OHRQoL has not been previously described in $\mathrm{Ku}-$ wait. Family caregivers, especially the parents of disabled children, report a variety of oral symptoms, daily life problems, and concerns attributable to their childrens' oral health that impact the child's and family's quality of life [24]. The parents of disabled children encounter con- stant stress at home and the teachers have pressure in dealing with these children at school. The aim of this study was to evaluate and compare by GOHAI the selfassessed oral health between the parents and the teachers of disabled schoolchildren in Kuwait.

\section{Subjects and Methods}

The participants in this study were the parents and the teachers of students from four schools for special needs; two Down syndrome and two physically disabled children's schools. Children in these schools had a high caries experience, poor oral hygiene and poor periodontal conditions in earlier studies [20,21].

Information was collected by structured anonymous questionnaires. Impact of perceived oral health was measured by 12 negative and positive GOHAI questions, which evaluated three dimensions of OHRQoL: (1) physical function, representing the pattern of eating, speech and swallowing; (2) pain or discomfort, representing the use of medication to relieve pain or discomfort, and (3) psychosocial function, representing the worry or concern about oral health, dissatisfaction with appearance, self-consciousness about oral health and avoidance of social contacts because of oral problems [5]. The GOHAI questions had a 3-point scale (always, sometimes, never) [25]. Using the methods described by Atchison and Dolan the GOHAI scores were computed $[5,26]$. The GOHAI score was determined by summing the final score of each of the 12 items ranging from 12 to 36 .

The questionnaire also included sociodemographic factors of the respondents, i.e. age at last birthday, nationality (Kuwaiti, non-Kuwaiti), residence (Capital, Hawally, Farwaniya, Ahmadi, Jahra, Mubarak Al Kabir), educational level and oral health behavior (toothbrushing frequency and visits to a dentist).

To validate the content, the questionnaire was translated from English to Arabic and then back-translated into English by two dentists who are fluent in both English and in Arabic. Ethical approval for this study was obtained by the Ethics Committee of the Faculty of Dentistry, Kuwait University. Self-administered questionnaires were distributed to the parents and the teachers of the disabled children in these schools. The questionnaires were taken by the children to their home, where their parents filled them out and returned them back to the school with their children. Altogether 335 parents and 150 teachers received the questionnaire. A covering letter explaining the purpose of the survey was included.

\section{Statistical Methods}

The data analysis of the study was carried out using SPSS statistical package (version 15). Frequency distributions for all variables were generated. GOHAI scores were compared by the following variables: age, nationality, residence, education level, child's school, toothbrushing frequency and visits to the dentist. Differences in the mean GOHAI scores were evaluated by test and analysis of variance (ANOVA). The Chi-square test was utilized to find out differences in percentage responses of the participants when the GOHAI was evaluated by individual questions. Pearson's correlation coefficient ( $r$ ) was used to measure the inter-item and item-scale correlations among all the respondents. The internal consistency was measured by Cronbach's alpha. The significance level used was $\mathrm{p}<0.05$. 
Table 1. The mean ( \pm SD) GOHAI of parents and teachers according to sociodemographic status and dental health habits

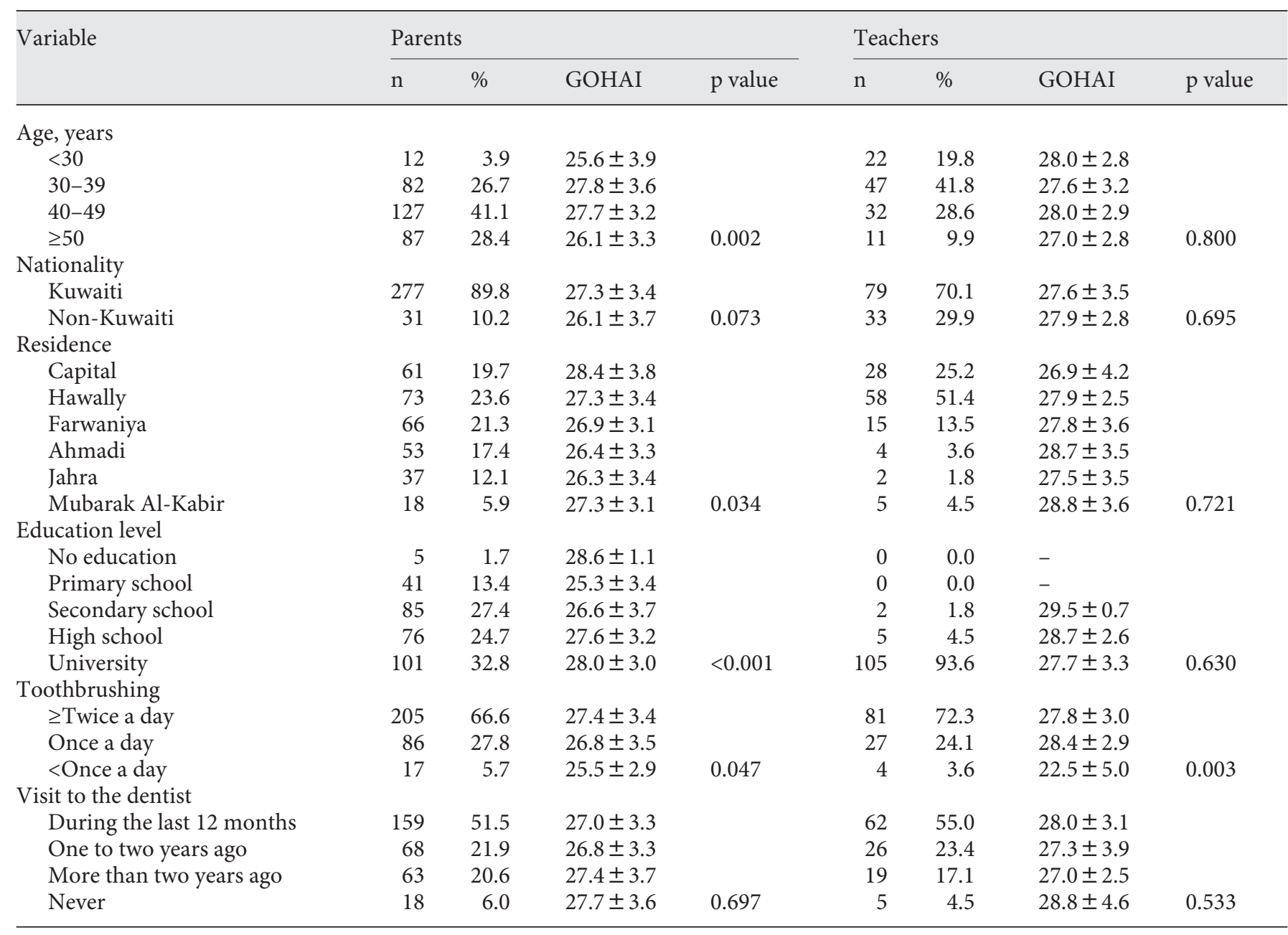

\section{Results}

Of 335 questionnaires distributed to the parents, 308 were completed, resulting in a $92 \%$ response rate; for teachers it was $112(75 \%)$ out of 150 distributions. The mean age of the parents was $45 \pm 9.9$ years and that of the teachers was $38 \pm 8.4$ years. One-hundred and twenty-seven $(127 ; 41 \%)$ of the parents were between 40 and 49 years and 47 (42\%) of the teachers were between 30 and 39 years (table 1). One-hundred and seventy-two (172; $56 \%)$ of the studied parents and $81(72 \%)$ of the teachers were females. Two-hundred and seventy-seven (277; 90\%) of the parents and 79 (70\%) of the teachers had Kuwaiti nationality. One third of the parents $(33 \% ; 101)$ and $94 \%$ (105) of the teachers had university education. One-hundred and fifty-nine $(159 ; 52 \%)$ parents, and 62 (55\%) teachers had visited a dentist during the last 12 months.
The mean GOHAI was $27.2 \pm 3.5$ among the parents and $27.8 \pm 3.3$ among the teachers $(\mathrm{p}=0.091)$. GOHAI scores were significantly higher $27.8 \pm 3.4$ in the older age groups (30-49 years) compared to parents less than 30 years of age $25.6 \pm 3.9(\mathrm{p}=0.002)$ (table 1). Parents residing in Capital governorate had a higher GOHAI 28.4 \pm 3.8 , compared to those residing in Jahra $26.3 \pm 3.4$ $(\mathrm{p}=0.034)$. Parents with a university education had higher GOHAI $28.1 \pm 3.1$ compared to those with just a primary education $25.3 \pm 3.4(\mathrm{p}<0.001)$. There was no difference between Kuwaiti and non-Kuwaiti respondents among the parents and teachers. There were differences in the mean GOHAI scores according to the toothbrushing frequency among parents $(\mathrm{p}=0.047)$ and teachers $(p=0.003)$. Higher GOHAI scores were found among the parents and the teachers who brushed their teeth more than once a day (table 1). The mean GOHAI did not dif- 
Table 2. Distribution (in \%) of the individual GOHAI items in parents and teachers

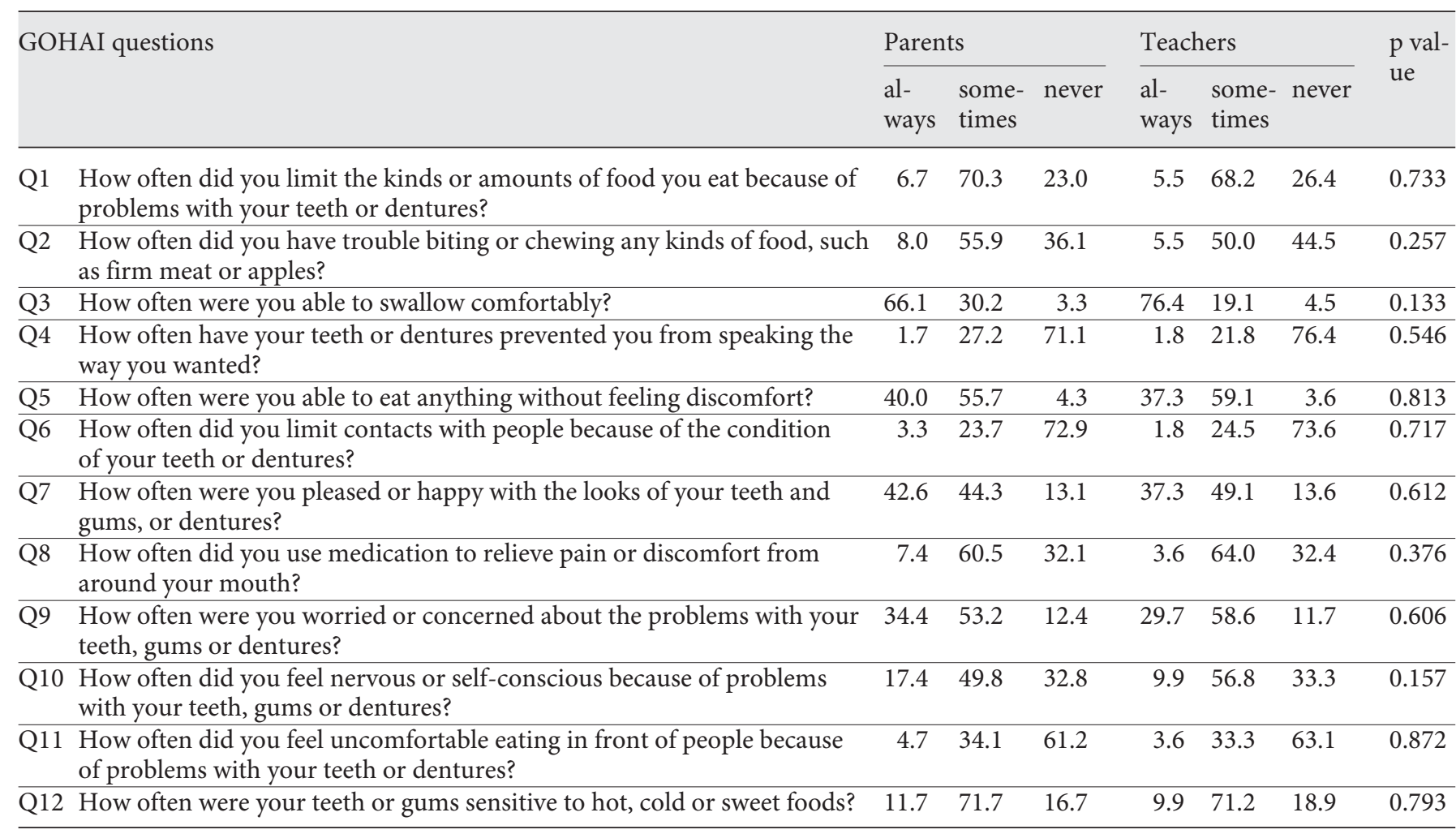

fer according to dental visits among the parents and the teachers.

There were no significant differences between the responses (answers) of the parents and the teachers on any of the 12 questions (table 2). Two thirds (66\%) of the parents and three fourths (76.4\%) of the teachers were always able to swallow comfortably. About $40 \%$ of the parents and $37 \%$ of the teachers were able to eat without discomfort. Altogether, $43 \%$ of the parents and $37 \%$ of the teachers were always pleased and happy with the looks of their teeth and gums, or dentures.

All the inter-item correlations were positive (table 3 ). The strongest inter-item correlations were observed between 'uncomfortable eating in front of people' and 'able to eat without discomfort' ( $\mathrm{r}=0.52)$; 'limit contacts with people' $(r=0.52)$ and 'self-conscious of teeth' $(r=0.48)$. There was also a strong correlation between 'being able to eat without discomfort' and 'having trouble biting or chewing' $(\mathrm{r}=0.46)$; 'being unable to speak clearly' $(\mathrm{r}=0.44)$. The weakest correlations were between 'being pleased with look of teeth' and 'limiting food because of teeth' $(\mathrm{r}=0.12)$. Cronbach's alpha (0.83) showed a high degree of internal consistency between different GOHAI items.

\section{Discussion}

The mean GOHAI score of this study was 27.2 among the parents and 27.8 among the teachers $(\mathrm{p}=0.091)$. There were no differences in the GOHAI scores between the parents and teachers even though a majority of the school teachers had a university education compared to about one third of the parents. This might be the strong cultural similarity of the living conditions of the both groups in Kuwait. There was a significant difference in the mean GOHAI score between the age groups and educational level among the parents. GOHAI was higher in university-educated parents compared to those with primary education, probably due to increased knowledge and coping skills of the parents. The 30-49 years of age group had higher GOHAI than the younger age group of the parents.

In the present study, higher GOHAI scores were associated with once-a-day toothbrushing frequency among the parents and with once-a-day or more frequent toothbrushing among the teachers. This finding is similar to the earlier study where poorer oral hygiene was associated with poorer oral health [22] and poor or 
Table 3. Correlations (r) of different GOHAI items (questions)

\begin{tabular}{|c|c|c|c|c|c|c|c|c|c|c|c|c|c|}
\hline Q1 & Limit kinds of food & 1.00 & & & & & & & & & & & \\
\hline Q2 & Trouble biting or chewing & $0.37^{\mathrm{a}}$ & 1.00 & & & & & & & & & & \\
\hline Q3 & Able to swallow comfortably & $0.34^{\mathrm{a}}$ & $0.36^{\mathrm{a}}$ & 1.00 & & & & & & & & & \\
\hline Q4 & Unable to speak clearly & $0.24^{\mathrm{a}}$ & $0.33^{\mathrm{a}}$ & $0.18^{\mathrm{a}}$ & 1.00 & & & & & & & & \\
\hline Q5 & Able to eat without discomfort & $0.34^{\mathrm{a}}$ & $0.46^{\mathrm{a}}$ & $0.20^{\mathrm{a}}$ & $0.44^{\mathrm{a}}$ & 1.00 & & & & & & & \\
\hline Q6 & Limit contacts with people & $0.15^{\mathrm{a}}$ & $0.28^{\mathrm{a}}$ & $0.13^{\mathrm{a}}$ & $0.40^{\mathrm{a}}$ & $0.38^{\mathrm{a}}$ & 1.00 & & & & & & \\
\hline Q8 & Used medication to relieve pain & $0.22^{\mathrm{a}}$ & $0.30^{\mathrm{a}}$ & $0.19^{\mathrm{a}}$ & $0.23^{\mathrm{a}}$ & $0.38^{\mathrm{a}}$ & $0.27^{\mathrm{a}}$ & $0.27^{\mathrm{a}}$ & 1.00 & & & & \\
\hline Q9 & Worried about teeth, gums, dentures & $0.21^{\mathrm{a}}$ & $0.26^{\mathrm{a}}$ & $0.08^{\mathrm{a}}$ & $0.22^{\mathrm{a}}$ & $0.36^{\mathrm{a}}$ & $0.15^{\mathrm{a}}$ & $0.17^{\mathrm{a}}$ & $0.21^{\mathrm{a}}$ & 1.00 & & & \\
\hline Q10 & Self-conscious of teeth, gums dentures & $0.27^{\mathrm{a}}$ & $0.40^{\mathrm{a}}$ & $0.10^{\mathrm{a}}$ & $0.29^{\mathrm{a}}$ & $0.42^{\mathrm{a}}$ & $0.39^{\mathrm{a}}$ & $0.38^{\mathrm{a}}$ & $0.33^{\mathrm{a}}$ & $0.45^{\mathrm{a}}$ & 1.00 & & \\
\hline Q11 & Uncomfortable eating in front of people & $0.24^{\mathrm{a}}$ & $0.41^{\mathrm{a}}$ & $0.17^{\mathrm{a}}$ & $0.47^{\mathrm{a}}$ & $0.52^{\mathrm{a}}$ & $0.52^{\mathrm{a}}$ & $0.36^{\mathrm{a}}$ & $0.32^{\mathrm{a}}$ & $0.25^{\mathrm{a}}$ & $0.48^{\mathrm{a}}$ & 1.00 & \\
\hline Q12 & Sensitive to hot/cold/sweet foods & $0.26^{\mathrm{a}}$ & $0.33^{\mathrm{a}}$ & $0.14^{\mathrm{a}}$ & $0.18^{\mathrm{a}}$ & $0.32^{\mathrm{a}}$ & $0.16^{\mathrm{a}}$ & $0.18^{\mathrm{a}}$ & $0.35^{\mathrm{a}}$ & $0.30^{\mathrm{a}}$ & $0.38^{\mathrm{a}}$ & $0.32^{\mathrm{a}}$ & 1.00 \\
\hline
\end{tabular}

a Correlation is significant at the 0.01 level; ${ }^{\mathrm{b}}$ correlation is significant at the 0.05 level.

low GOHAI scores are expected for those having poor oral health [27].

There was no difference in the responses between the parents and the teachers on any of the 12 items of the GOHAI individual questions. Also, in an earlier study by Atchison and Dolan (1990) [26] there was no difference noted by dentition status among subjects in feeling happy with their appearance, worrying about their teeth or speaking. However in this study, people with natural teeth had a higher GOHAI score and demonstrated significantly fewer problems with limiting their food choices, with trouble biting and chewing or eating without discomfort, and with sensitivity to temperature, and also experienced fewer psychosocial problems [26].

The results of this study showed an excellent internal consistency of the studied GOHAI items (0.83). In another study, reliability and validity of the GOHAI was acceptable with Cronbach's alpha of 0.79 [26]. Internal consistency was high in this study and comparable with that of other GOHAI versions [7-9, 12]. The internal consistency with Cronbach's alpha of 0.83 was higher than the recommended value of 0.70 as sufficient internal consistency [28]. Also, all the inter-item correlations were positive. The strongest inter-item correlations were between 'uncomfortable eating in front of people', 'selfconscious of teeth, gums, dentures' and 'able to eat without discomfort'. These items could be considered as psychosocial items emphasisizing subjective self-confidence.

In this study, we wanted to detect any possible differences in the impact of perceived oral health between the parents and teachers of disabled children. The study did not include schools of nondisabled children and therefore the results cannot be generalized to the Kuwaiti population, which is a limitation of the study. Another limitation was that objective oral health assessment of the subjects could not be done due to practical difficulties and limited accessability to parents. The children took the questionnaires to their home, where their parents filled them out and returned them back to the school with their children. Parents seldom visit the school and the children are more likely to be accompanied by their maids.

\section{Conclusion}

Oral health had a relatively weak impact on the quality of life of these adults. There seemed to be no difference in the impact of perceived oral health on the quality of life between the parents and the teachers of these disabled children.

\section{Acknowledgement}

Our warmest thanks to all the parents and teachers of the schoolchildren who participated in this study. We gratefully acknowledge Dr. Eman Al-Menezaa and Nameer Al-Sahli for the translation of the questionnaire. We express special thanks to the school principals, and the education authorities who helped in the administration of this study. 


\section{References}

1 Fitzpatrick R, Fletcher A, Gore S, Jones D, Spiegelhalter D, Cox D: Quality of life measures in health care. Br Med J 1992;305:10741077.

$>2$ Buck D, Newton JT: Non-clinical outcome measures in dentistry: publishing trends 1988-98. Community Dent Oral Epidemiol 2001;29:2-8.

3 Slade GD: Measuring oral health and quality of life. Chapel Hill: University of North Carolina, Dental Ecology, 1997.

$\checkmark 4$ Slade GD: Derivation and validation of a short-form oral health impact profile. Community Dent Oral Epidemiol 1997;25:284290.

5 Atchison KA: The General Oral Health Assessment Index. In Slade GD (ed): Measuring Oral Health and Quality of Life. Chapel Hill: University of North Carolina,1997, pp 7180.

6 Atchison KA, Der-Martirosian C, Gift H: Components of self-reported oral health and general health in racial and ethnic groups. J Public Health Dent 1998;58:301-307.

$>7$ Wong MC, Liu JK, Lo EC: Translation and validation of the Chinese version of the $\mathrm{GO}$ HAI. J Public Health Dent 2002;62:78-83.

$>8$ Tubert-Jeannin S, Riordan PJ, Morel-Papernot A, Porcheray S, Saby-Collet S: Validation of an oral health quality of life index (GOHAI) in France. Community Dent Oral Epidemiol 2003;31:275-284.

$>9$ Hagglin C, Berggren U, Lundgren J: A Swedish version of the GOHAI index. Psychometric properties and validation. Swed Dent J 2005;29:113-124.
10 Naito M, Suzukamo Y, Nakayama T, Hamajima N, Fukuhara S: Linguistic adaptation and validation of the General Oral Health Assessment Index (GOHAI) in an elderly Japanese population. J Public Health Dent 2006;66:273-275.

11 Othman WN, Muttalib KA, Bakri R, Doss JG, Jaafar N, Salleh NC, Chen S: Validation of the Geriatric Oral Health Assessment In dex (GOHAI) in the Malay language. J Public Health Dent 2006;66:199-204.

12 Hassel AJ, Rolko C, Koke U, Lesien J, Rammelsberg P: A German version of the GOHAI. Community Dent Oral Epidemiol 2008;36:34-42.

13 Atieh MA: Arabic version of the geriatric oral health assessment index. Gerodontology 2008;25:34-41.

-14 Matthias RE, Atchison KA, Schweitzer SO, Lubben JE, Mayer-Oakes A, De Jong F: Comparisons between dentist rating and self-ratings of dental appearance in an elderly population. Spec Care Dentist 1993;13:53-60.

-15 Locker D, Matear D, Stephen M, Lawrence $\mathrm{H}$, Payne B: Comparison of the GOHAI and OHIP-14 as measures of the oral health-related quality of life of the elderly. Community Dent Oral Epidemiol 2001;29:373-381.

16 McGrath C, Alkhatib MN, Al-Munif M, Bedi R, Zaki AS: Translation and validation of an Arabic version of the UK oral health related quality of life measure (OHQoL-UK) in Syria, Egypt and Saudi Arabia. Community Dent Health 2003;20:241-245.

17 Daradkeh S, Khader YS: Translation and validation of the Arabic version of the Geriatric Oral Health Assessment Index (GOHAI). J Oral Sci 2008;50:453-459.

-18 Al-Mutawa SA, Shyama M, Al-Duwairy Y, Soparkar P: Dental caries experience of Kuwaiti schoolchildren. Community Dent Health 2006;23:31-36.
19 Behbehani JM, Shah NM: Oral health in Kuwait before the Gulf war. Med Princ Pract 2002;11(suppl 1):36-43.

20 Shyama M, Al-Mutawa SA, Honkala S, Sugathan T, Honkala E: Oral hygiene and periodontal conditions in special needs children and young adults in Kuwait. J Disabil Oral Health 2000;1:13-19.

21 Shyama M, Al-Mutawa SA, Morris RE, Sugathan T, Honkala E: Dental caries experience of disabled children and young adults in $\mathrm{Ku}$ wait. Community Dent Health 2001;18:181186.

22 Al-Shammari KF, Al-Ansari JM, Al-Khabbaz AK, Dashti A, Honkala EJ: Self-reported oral hygiene habits and oral health problems of Kuwaiti adults. Med Princ Pract 2007;16: 15-21.

23 Gift HC, Atchison KA, Dayton CM: Conceptualizing oral health and oral health related quality of life. Soc Sci Med 1997;44:601-608.

24 Baens-Ferrer C, Roseman MM, Dumas HM, Haley SM: Parental perceptions of oral health-related quality of life for children with special needs: impact of oral rehabilitation under general anesthesia. Pediatr Dent 2005;27:137-142.

25 Kressin NR: Associations among different assessments of oral health outcomes. J Dent Educ 1996;60:501-507.

26 Atchison KA, Dolan TA: Development of the Geriatric Oral Health Assessment Index. J Dent Educ 1990;54:680-687.

27 Kapur KK, Soman SD: Masticatory performance and efficiency in denture wearers. J Prosthet Dent 1964;14:686-694.

28 Bland JM, Altman DG: Cronbach's alpha. Br Med J 1997;314:572. 